\title{
EM VACAS LEITEIRAS A IDADE É MAIS IMPORTANTE QUE O CHIFRE PARA DETERMINAR O ACESSO A SUPLEMENTAÇÃO NO COCHO
}

(For dairy cows age is more important than horns to determine the access to feed supplementation)

\author{
Matheus Deniz, Karolini Tenffen de Sousa, Deise Taborda Martins, Vitória Alves Branco Riezemberg, Barbara \\ Haline Buss Baiak, Marcos Martinez do Vale, João Ricardo Dittrich \\ Universidade Federal do Paraná, Curitiba, Paraná, Brasil.
}

*Correspondência: matheus-utfpr@hotmail.com

RESUMO: A descorna é uma prática comum na bovinocultura de leite, na qual geralmente não são utilizadas técnicas, como anestesia e analgesia para aliviar a dor dos animais. No Brasil, a descorna é proibida na produção animal orgânica. Porém, existe preocupação com a presença de animais com chifres no rebanho, pois pode aumentar o risco de lesões durante a alimentação, devido as disputas por acesso ao alimento. No entanto, se adaptarmos as instalações e melhorar as condições de manejo, pode não ser necessário sujeitar os animais a esse procedimento doloroso. Assim, o objetivo deste estudo foi avaliar a influência da idade e a presença de chifre no acesso a suplementação no cocho. O estudo foi realizado na Estação de Pesquisa Agroecológica - CPRA, do Instituto de Desenvolvimento Rural do Paraná, em Pinhais, Brasil. Participaram deste estudo 27 vacas (7 com chifre e 20 mochas) mestiças (Jersolando) em lactação, com idade média de $54 \pm 24$ (média \pm DP) meses e peso médio de $410 \mathrm{~kg} \pm 41$. As observações foram realizadas na área de alimentação por 13 dias não consecutivos em julho de 2019, com duração de uma hora ( $8 \mathrm{~h}$ - 9h). Silagem de milho foi fornecida em um cocho de concreto $(27 \mathrm{~m})$ com um espaço linear de $1 \mathrm{~m} /$ animal e água foi fornecida ad libitum. O tempo no cocho foi registrado por scan-sampling a cada um minuto e as interações agonísticas foram registradas sempre que ocorreram. Para análise dos dados, dividimos os animais em três categorias de acordo com a idade: jovens: $2-3$ anos $(n=8)$, intermediário: 4-5 anos $(n=12)$ e mais velhos: 6-10 anos $(n=7)$. Para eliminar a discrepância numérica entre as categorias de idade, a frequência no cocho (\%) foi balanceada de acordo com o número de animais em cada categoria. Análises de influência foram realizadas por Modelos Lineares Generalizados e uma correlação de Spearman foi usada para examinar a relação entre as categorias e a frequência no cocho. Todas as análises foram realizadas com $95 \%$ de confiança pelo software R. Não houve diferença $(p>0,05)$ entre o peso das três categorias; animais jovens apresentaram peso médio de 406,7 $\pm 45,4 \mathrm{~kg}$, os intermediários pesaram $409 \pm 42,1 \mathrm{~kg}$ e os mais velhos $404 \pm 49,3 \mathrm{~kg}$. Houve correlação $(p<0,05)$ do tempo no cocho com a idade $(r=0,37)$ e presença de chifre $(r=-0,57)$. Todos os animais com chifre se concentraram na categoria dos mais jovens e tiveram menor frequência no cocho $(p<0,05)$. Os animais mais jovens foram as principais vítimas (70\%) das interações agonísticas, seguido dos intermediários (44\%) e os mais velhos (33\%). Não houve diferença $(p>0,05)$ na frequência no cocho entre os animais intermediários $(80 \%)$ e os mais velhos (77\%), porém os animais mais velhos foram os principais instigadores (67\%), direcionando principalmente energia para deslocar os animais mais jovens para fora do cocho. A idade foi mais importante que a presença de chifre para determinar o acesso das vacas leiteiras ao suplemento no cocho.

Palavras-chave: bem-estar; cornos; etologia aplicada; hierarquia-social.

Agradecimentos: Coordenação de Aperfeiçoamento de Pessoal de Nível Superior (CAPES) pela bolsa concedida ao primeiro autor. Ao Evandro M. Richter e João A. G. Hill pela oportunidade de realizar este trabalho no CPRA.

Nota: Este trabalho foi aprovado pela Comissão de Ética no Uso de Animais da Universidade Federal do Paraná sob protocolo número 083/2018. 